Linguiística

Vol. 32-2, diciembre 2016: 63-72

ISSN 2079-312X en línea

ISSN 1132-0214 impresa

DOI: $10.5935 / 2079-312 X .20160017$

\title{
PALATALIZAÇÃO DE $L$ DIANTE DE I NO PORTUGUÊS BRASILEIRO
}

\author{
PALATALIZATION OF $L$ BEFORE $I$ IN BRAZILIAN PORTUGUESE
}

\author{
Marilucia Barros de Oliveira \\ Universidade Federal do Pará/UFPA \\ mariluci@ufpa.br \\ Alcides Fernandes de Lima \\ Universidade Federal do Pará/UFPA \\ alcides@ufpa.br \\ Abdelhak Razky \\ Universidade Federal do Pará/UFPA \\ arazky@gmail.com
}

Neste trabalho, descreve-se o perfil da realização variável da lateral /l/ diante de $[\mathrm{i} / \mathrm{j}]$ nas capitais brasileiras (excetuando Palmas e DF), considerando-se fatores linguísticos (contexto CVV, como família, sandália, mobília; e CV, como livro, liquidação, militar) e sociodialetais (sexo, idade, escolaridade, capitais, regiões). Trata-se de um mapeamento geossociolinguístico da variação fonética do /l/ nas 25 capitais que foram ponto de inquérito do Atlas Linguístico do Brasil. As 1.725 ocorrências da variável /// extraídas da fala de 200 informantes foram submetidas a análises estatísticas no programa GoldVarb, para se medir a relevância dos fatores geossociolinguísticos no condicionamento das variantes [ 1 ] e $[\lambda]$. Os resultados das análises mostram uma preponderância do fator dialetal (capitais) sobre os fatores sociais (sexo, idade e escolaridade) no condicionamento da palatalização de /1/.

Palavras-chave: Atlas Linguístico do Brasil, Variação fonética, Palatalização do /1/

Key words: Linguistic Atlas of Brazil, Phonetic variation, Palatalization of /1/

This paper describes the profile of the variable realization of the lateral $/ \mathrm{l} /$ before $[\mathrm{i} / \mathrm{j}]$ in allbrazilian capital cities except Palmas and DF, taking into considerationthe linguistic factors CVV context as família, sandália, mobília (family, sandal, furniture respectively) and CV context as in livro, liquidação, military (book, settlement, military), as well as the sociodialectal variables likegender, age, education, capital city and regions. It is a geosociolinguitic mapping of phonetic variation of /l/ in 25 capitals that are survey points for the Linguistic Atlas of Brazil. The 1725 variable occurrences of $/ 1 /$, extracted from the speech of 200 informants, were submitted to a statistical analysis in GoldVarb program to measure the relevance of geosociolinguistic factors involved in the realization of the variants $[1]$ and $[\lambda]$. The results show a preponderance of dialectal factor (capital) on social factors (gender, age and education) in the conditioning of the palatalization of $/ 1 /$.

(Recibido: 19/01/2016; Aceptado: 27/05/2016) 


\section{INTRODUÇÃO}

Como se sabe, no latim clássico não havia consoantes palatais, a palatalização surge como inovação no latim imperial, de onde deriva a língua portuguesa ${ }^{1}$. É da passagem do latim para o português que surgem, nesta língua, as quatro consoantes palatais $-/ \int, 3, \Lambda, \mathrm{j} /$ - que criam oposição distintiva como em acha/assa, aja/asa, sonho/sono, malha/mala. O surgimento dessas consoantes, no português, está relacionado a fenômenos de palatalização de consoantes (ou grupos consonânticos) existentes em latim, como se pode observar em exemplos como somnio > sonho, ciconia > cegonha; inflare > inchar, flamma > chama; hodie > hoje; spongia > esponja; veclo > velho, apicla > abelha, miliu > milho. Com relação especificamente ao /K/, Camara Jr. (1977) observa que os segmentos fônicos latinos -lia, -lie, -lio passam ao português como -lha, -lhe, -lho (1 $>$ lh): folia > folha, muliere > mulher, filiu > filho.

Esse processo de palatalização, que deu origem aos fonemas palatais do português, permanece bastante manifesto no Português Brasileiro (PB), atuando, sobretudo, em consoantes com alguma oclusão alveolar ${ }^{2}$ seguidas de [i/j], como se pode observar em tia $\left.>[\mathrm{t}\}\right] \mathrm{ia}$, dia $>[\mathrm{d} 3] \mathrm{ia}$, sandália $>$ sanda $[\Lambda]$ a, livro $>[\Lambda]$ ivro, nível $>[3]$ ível $^{3}$.

O presente trabalho mostra um perfil da realização variável de /// antes de [i/j] nas capitais brasileiras (excetuando Palmas e Distrito Federal), considerando fatores linguísticos e sociodialetais.

Os dados para esse estudo fazem parte do corpus do Projeto Atlas Linguístico do Brasil (ALiB). O Projeto ALiB, iniciado em 1996, envolve várias dezenas de pesquisadores de todo o Brasil, provenientes de 16 universidades (11 federais e 5 estaduais) que assinaram o convênio para a realização do maior projeto de pesquisa sobre $\mathrm{PB}$. O projeto está sob a coordenação geral de um Comitê Científico Nacional, presidido pela professora Suzana Alice Marcelino da Silva Cardoso (cf. Cardoso et al., 2014). Ao todo são 1.100 informantes/moradores de 250 localidades do país, distribuídas do Oiapoque (ponto 001) ao Chuí (ponto 250) ${ }^{4}$.

\section{DESCRIÇÃO DO FENÔMENO}

Neste trabalho, analisa-se a palatalização do /l/ diante de [i/j] em 25 capitais brasileiras. Os dados para esse estudo foram obtidos das respostas fornecidas por 200 informantes (8 de cada capital) aos questionários Fonético Fonológico (QFF) (p. ex.: liquidificador, liquidação, família e sandália) e Semântico Lexical (QSL) (p. ex.: galinha, estilingue, bolita, aliança).

A preparação dos dados fonéticos do ALiB tem duas fases: (i) a da transcrição fonética e a (ii) da exposição dos resultados, em workshop nacional do ALiB, para que estes sejam analisados e debatidos pelo Comitê Nacional juntamente com os demais pesquisadores do projeto.

\footnotetext{
${ }^{1}$ Nas palavras de Teyssier (2001, p. 11): "Entre as inovações fonéticas do latim imperial, algumas terão consequências importantíssimas. É o caso da palatalização".

${ }^{2}$ E mesmo, com menos frequência, em não alveolares: quiabo $>\left[\mathrm{k}^{\mathrm{j}}\right]$ iabo, guitarra $>\left[\mathrm{g}^{\mathrm{j}}\right]$ itarra.

${ }^{3}$ Com [n], em contexto interno, parece haver uma tendência à vocalização: banha > bãja, amanhã > amãjã, sonho > sõjo; ressurgindo plenamente, da palatalização de [n], em outros contextos: ninho > [n]inho, menino > me[j]ino, nível > [n]ível, animo $>\mathrm{a}[\mathrm{n}]$ imo.

${ }^{4}$ Para mais informações, consultar o site www.alib.ufba.br.
} 
A fase da transcrição fonética tem, por sua vez, três etapas: (i) primeira transcrição fonética, feita pelas equipes regionais; (ii) segunda transcrição fonética, realizada pela equipe regional responsável pela análise do fenômeno; (iii) terceira transcrição fonética, realizada pelos pesquisadores responsáveis pela redação final dos artigos. Os dados analisados neste presente trabalho passaram por essas fases.

Ao todo foram analisadas 1.725 ocorrências, referentes à palatalização de /l/ diante de [i/j]. Esses dados foram submetidos ao programa GoldVarb, para se obter os resultados estatísticos. As variáveis foram organizadas conforme descritas a seguir:

- Variável dependente: $\langle 1>$ e suas variantes palatal $[K]$ e alveolar [1].

- Variáveis independentes:

○ Região: Norte, Nordeste, Sul, Sudeste e Centro-oeste;

○ Estado: capitais brasileiras, excetuando Palmas (capital do Tocantins) e DF;

- Faixa etária: de 18 a 30 (A) e de 50 a 65 (B);

○ Sexo: feminino e masculino;

○ Escolaridade: fundamental (I) e superior (II);

○ Estrutura silábica: CV (p. ex.: livro, bolita) e CVV (p. ex.: família, sandália).

Os resultados das análises estatísticas serviram de base para a descrição e mapeamento da variação geossociolinguística da palatalização do /l/ diante de [i/j].

A opção pelo uso da frequência, ao invés do peso relativo, deveu-se ao fato de se considerar aquela mais adequada à leitura de cartas linguísticas e por se entender que a frequência atende melhor ao objetivo principal do presente estudo, que é traçar um perfil diatópico da palatalização de /l/ no PB.

Os resultados são apresentados em gráficos e cartas linguísticas, por meio dos quais é possível visualizar um contorno diatópico e diastrático da palatalização de /l/ diante de [i/j] nas capitais e regiões brasileiras.

\section{ANÁLISE DOS RESULTADOS}

A palatalização de consoantes oclusivas diante de [i/j] já é bem conhecida no PB, especialmente quando se trata da palatalização de /t/ e /d/. Sabe-se, de outra parte, que a palatalização diante [j] é bem mais frequente do que a diante [i], alcançando, de acordo com alguns estudos, índices muitos elevados, em alguns casos, quase categóricos (cf. Oliveira, 2007).

Esse condicionamento, de acordo com Oliveira (2007), está relacionado ao fato de segmentos mais constritos serem mais suscetíveis à palatalização. Assim, o contexto [1+j] seria mais propenso à palatalização do que $[1+i]$.

Tomando isso como hipótese, e no sentido de dar mais rigor a este estudo, procedeu-se a duas rodadas preliminares: numa, levou-se em consideração a presença de contexto que apresentava a estrutura CVV (como em família, sandália) e a estrutura CV (como em livro, bolita); noutra, considerou-se apenas o contexto com a estrutura CV (excluindo-se o contexto com estrutura CVV).

A seguir, os gráficos com os resultados dessa primeira análise. 


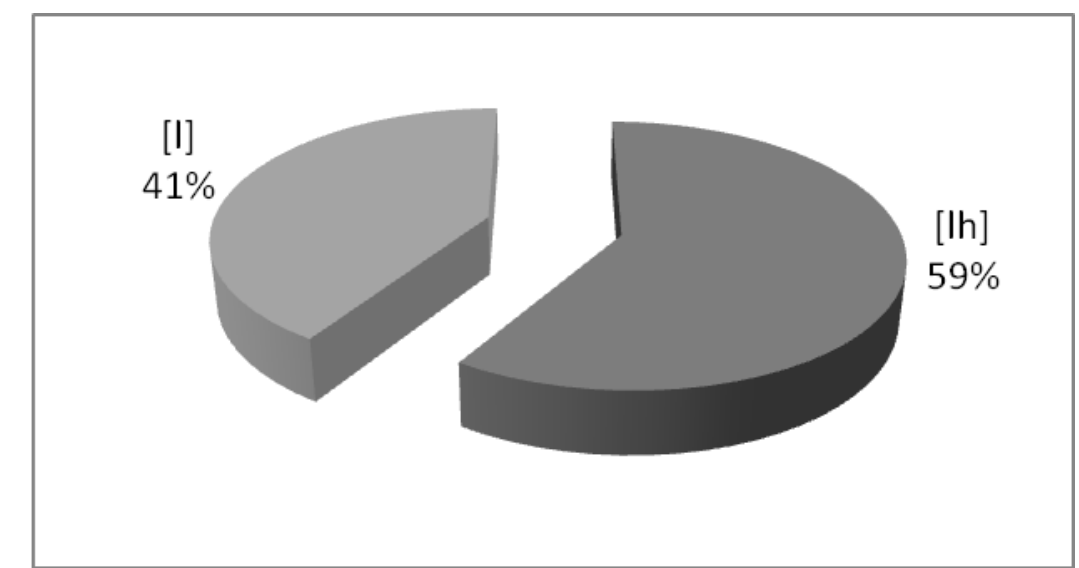

Gráfico 01: ocorrência da palatalização, considerando-se a estrutura CVV + CV.

Como se pode notar, quando são considerados os contextos CVV e CV, a palatalização de /l/ alcança, nas capitais, 59\% de frequência, contra $41 \%$ de alveolar. Todavia, quando são retiradas do cálculo global as palavras com estrutura CVV (sandália, família), esses percentuais mudam significativamente, como será mostrado a diante.

Na verdade, dos 367 dados que apresentam a estrutura CVV, apenas 9 ocorreram como [1], 14 sofreram apagamento e o restante (344) ocorreu como $[\lambda]^{5}$, isto é, os dados com estrutura CVV apresentam (excluindo o apagamento) 97,5\% de palatalização, contra 2,5\% de alveolar. Observando essa distorção que os dados com estrutura CVV criam sobre os resultados finais da análise e considerando ainda que os dados com essa estrutura se originam basicamente das palavras sandália e família, pareceu mais adequado retirar esse contexto das rodadas seguintes, a fim de se garantirem resultados mais consistentes na análise.

A seguir, apresenta-se o gráfico com a segunda rodada, já sem os dados com estrutura CVV. O total de dados (sem as palavras com estrutura CVV), para as 25 capitais, é de 1.358. São esses dados que serão usados nas análises a partir daqui.

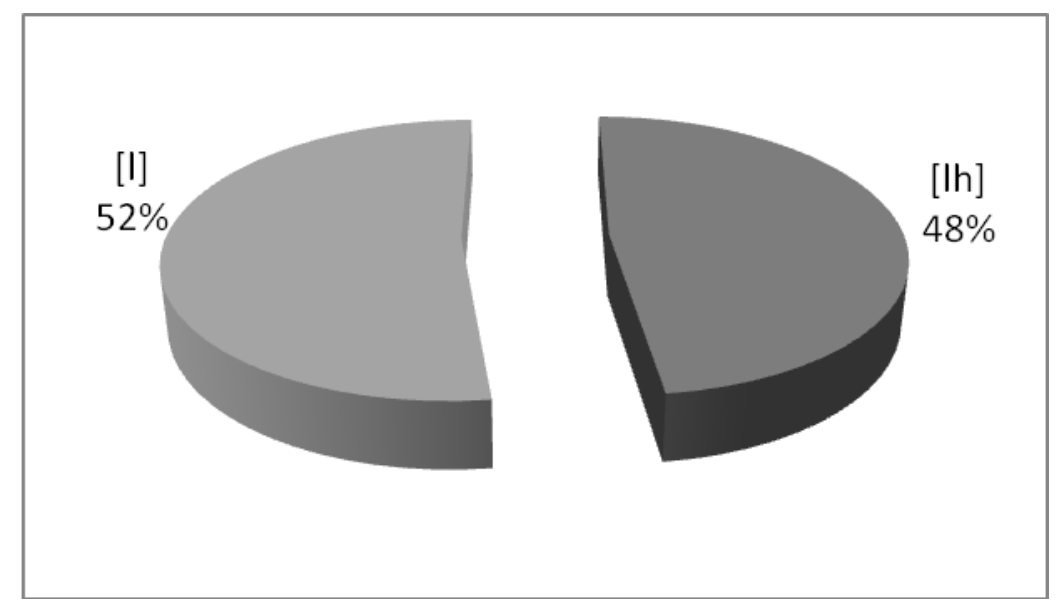

Gráfico 02: ocorrência da palatalização, considerando-se apenas a estrutura CV.

Como se pode visualizar no gráfico 02 , quando retirados os contextos em que há palatalização quase categórica de /1/ (a estrutura CVV), a frequência da palatalização cai, apesar de a distância entre as frequências para as duas variantes ainda permanecer bem aproximada: $52 \%$ para a variante alveolar contra $48 \%$ para a variante palatal.

\footnotetext{
${ }^{5}$ Não raro ocorre, neste contexto, após a aplicação da palatalização, o apagamento da semivogal que desencadeou o processo de palatalização de $/ 1 /$.
} 
Obviamente esse é apenas um resultado bruto. Como se mostrará adiante, há capitais em que a palatalização está em estágio bem avançado, capitais em que seu uso se aproxima do que se vê nos índices gerais aqui apresentados, e outras em que a variante alveolar ainda resiste firmemente à palatalização.

A seguir, apresentam-se as frequências da palatalização em função da região:

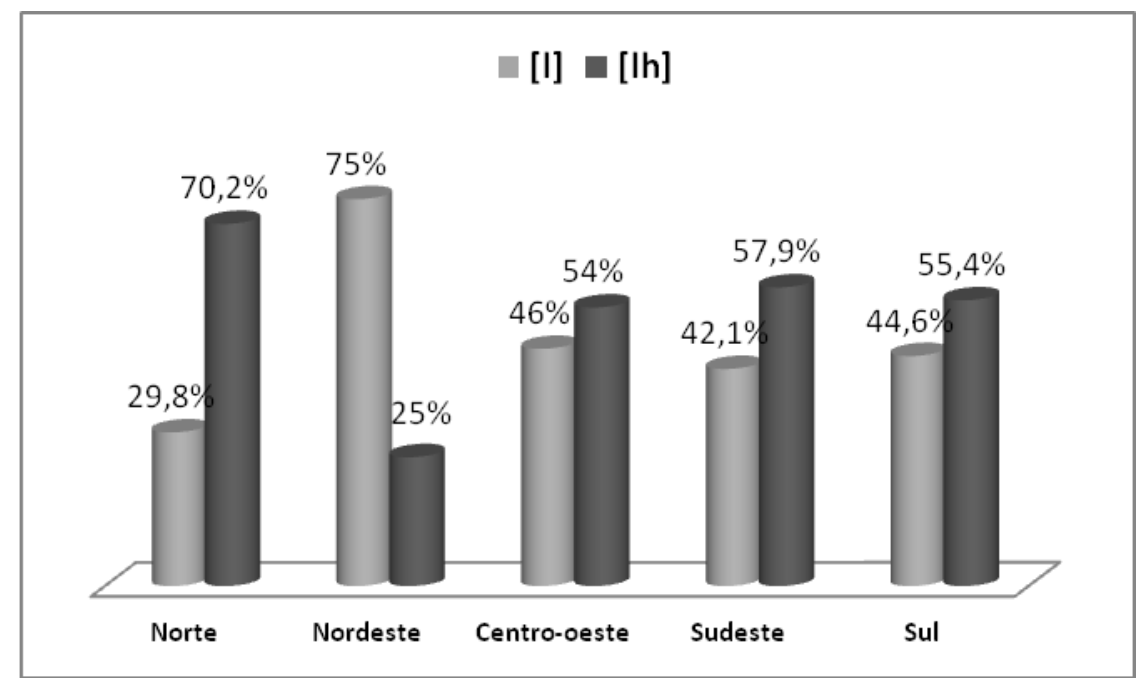

Gráfico 03: frequência da palatalização nas regiões brasileiras.

Os dados organizados por região detalham as diferenças mencionadas anteriormente. No Norte, a palatalização alcança um índice bem elevado, igual a 70,2\%. O predomínio da palatalização é seguido pelo Sudeste, com 57,9\%; pelo Sul, com 55,4\%; e pelo Centro-oeste, com $54 \%$. O Nordeste, com $25 \%$ de palatalização, é a única região cuja frequência fica abaixo de $50 \%$.

Esse índice de $25 \%$ de palatalização do Nordeste destoa das demais regiões do Brasil, mais destoa especialmente da região Norte, o que demonstra que essas duas regiões, apesar de geograficamente próximas, são linguisticamente distantes.

Excetuando, portanto, o Nordeste, nas demais regiões do Brasil a variante palatal já é mais usada do que a variante alveolar. $\mathrm{O}$ mapa que segue, ajuda a visualizar melhor essa distribuição. 


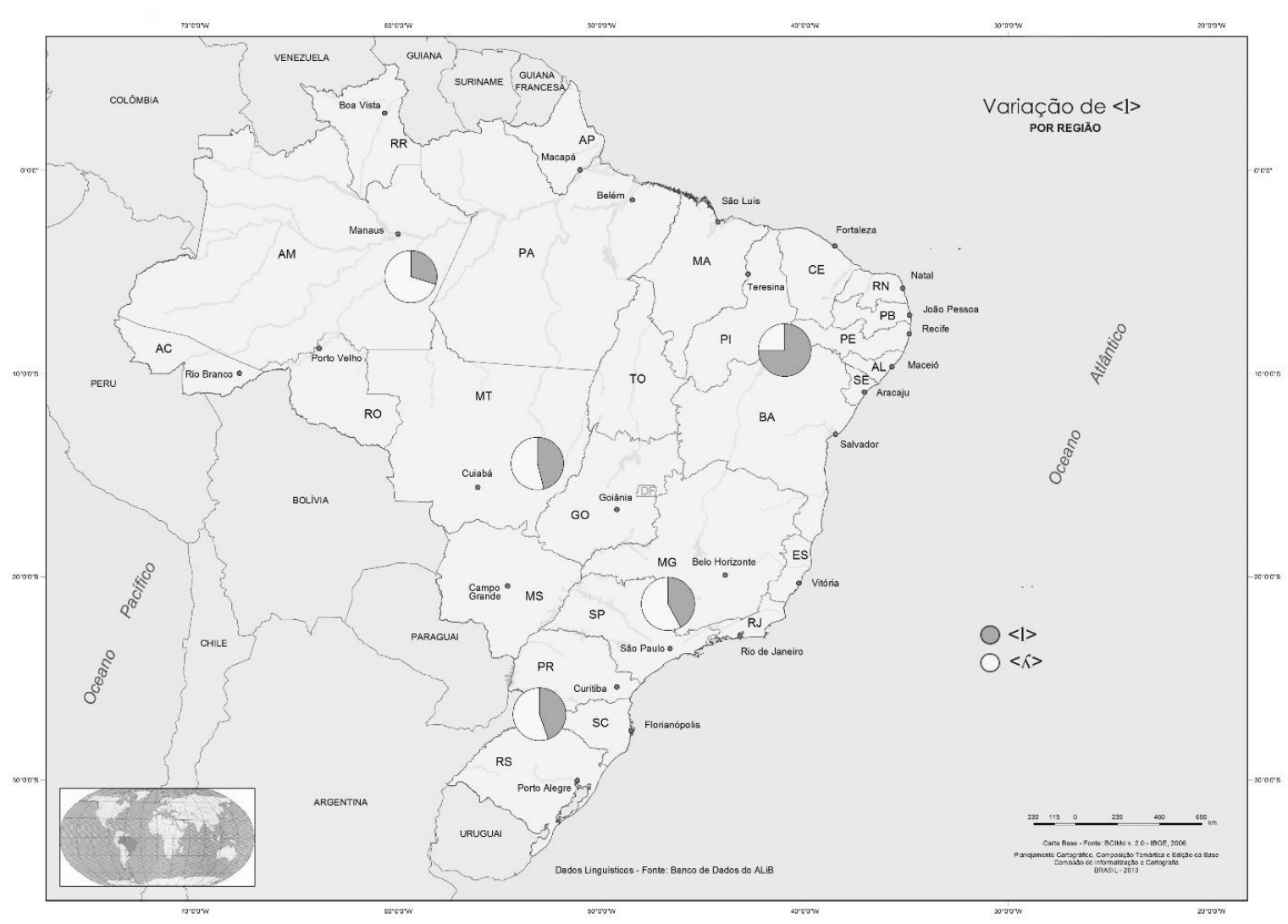

Figura 01: contornos diatópicos da palatalização de /1/ nas regiões brasileiras.

Observe-se que Norte e Nordeste são antagônicos quanto ao uso da variante alveolar. Do Centro-oeste ao Sul, passando-se pelo Sudeste, a palatalização de /1/ apresenta contornos semelhantes, havendo um equilíbrio entre as duas variantes nas três regiões.

Já no Nordeste e Norte as distâncias no uso dessas variantes são bastante significantes. Esses distanciamentos podem ser mais bem visualizados no gráfico a seguir.

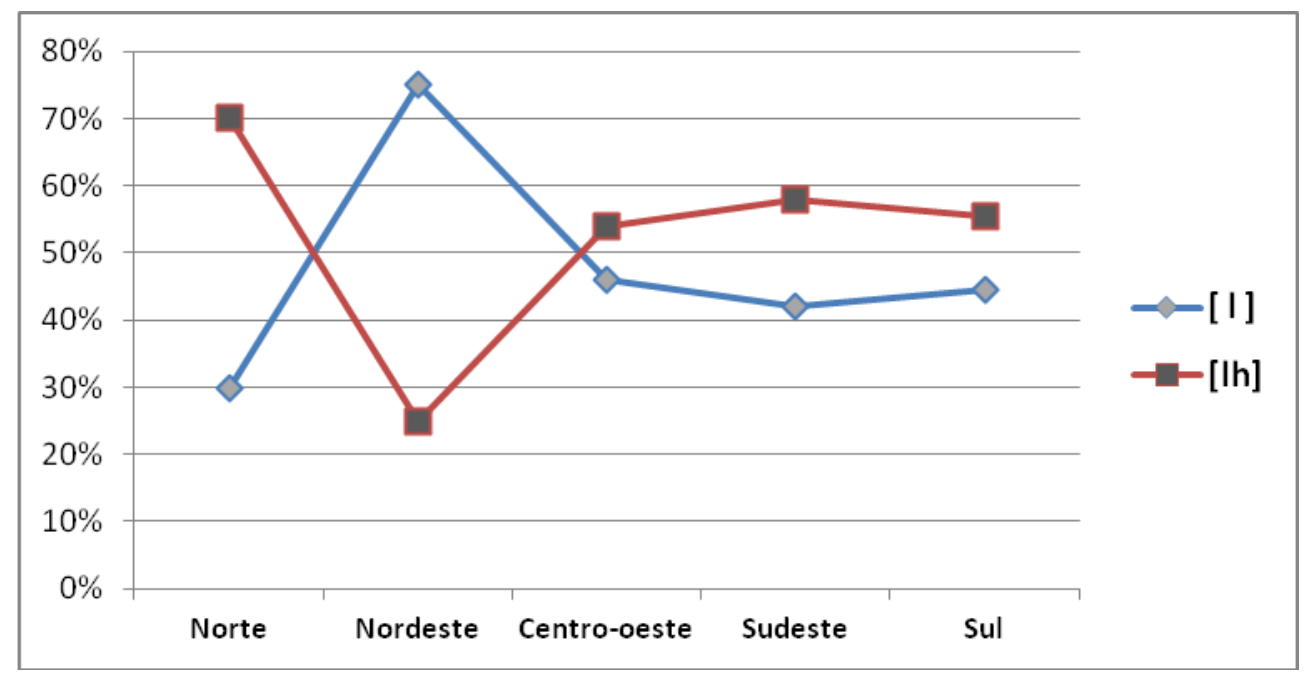

Gráfico 04: distância entre variantes palatal e alveolar, por região.

Todavia, as regiões, tomadas assim em conjunto, escondem diferenças bastante relevantes entre as capitais de uma mesma região, diferenças que só podem ser vistas com um maior refinamento da análise. 
No gráfico a seguir, observa-se Rio Branco (no Norte), com 78,7\% de alveolar ${ }^{6}$; Fortaleza (no Nordeste), com 44,4\% de palatal; e Florianópolis (no Sul), com 81,8\% de alveolar.

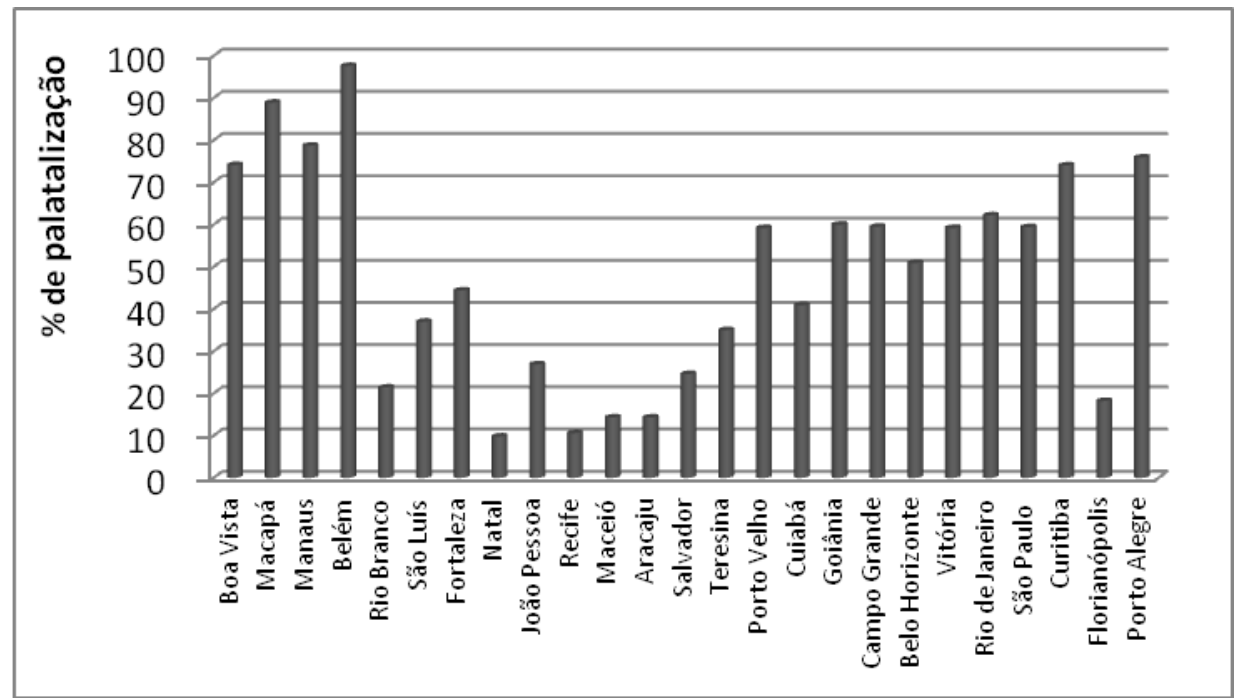

Gráfico 05: distribuição da palatalização nas capitais brasileiras.

Há capitais em que a palatalização é extremamente elevada, como Belém (97,6\%, o mais alto índice dentre todas as capitais), Macapá $(88,9 \%)$ e Porto Alegre $(75,9 \%)$, e outras em que é bem baixa, como Natal $(9,8 \%$, o índice geral mais baixo), Recife $(10,6 \%)$ e Aracaju (14,3\%). Considerando as capitais que despontam em palatalização em cada região: no Norte, temos Belém (97,6\%); no Nordeste, Fortaleza (44,4\%); no Centro-oeste, Goiânia (60\%); no Sudeste, Rio de Janeiro (62,5\%); e no Sul, Porto Alegre (75,9\%).

Com base no mapeamento desses índices, observa-se que enquanto o Norte apresenta preferência pela variante palatal, o Nordeste opta pela alveolar, e a região central e sul do país acomoda as duas variantes de forma mais equilibrada. $\mathrm{O}$ cartograma que segue mostra a variação de /l/ por capital.

\footnotetext{
${ }^{6}$ Esse altíssimo índice de alveolar em Rio Branco talvez possa ser explicado pelo grande número de imigrantes maranhenses que a cidade recebeu, por volta das décadas de 40 e 50, devido à política do governo federal para ocupar, na época, o Território Federal do Rio Branco.
} 


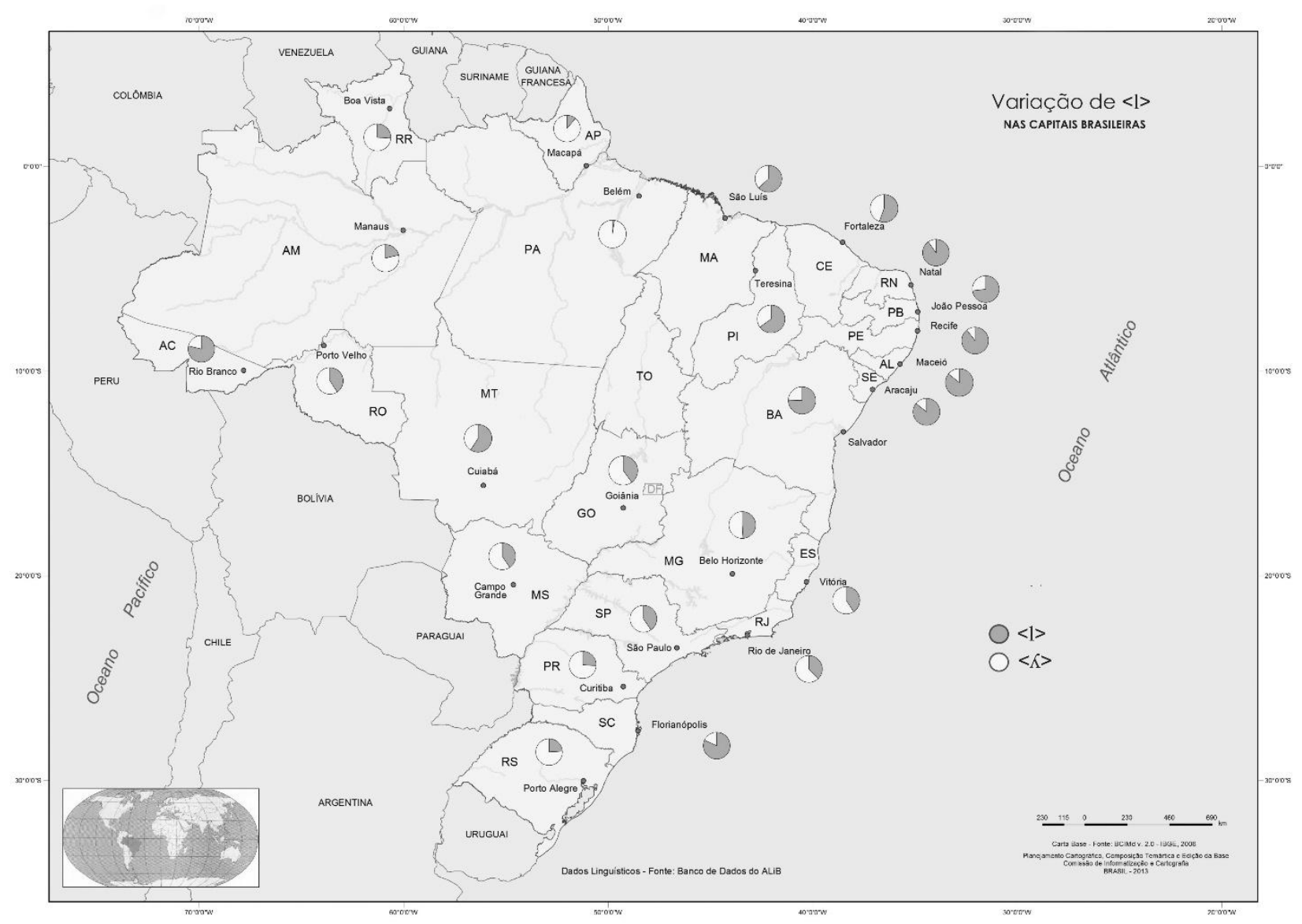

Figura 02: contornos diatópicos da palatalização de /1/ nas capitais brasileiras.

Quando se refina mais esses resultados, pode-se aferir o efeito de outras variantes externas sobre a palatalização de /// nessas capitais do Brasil. A seguir, apresentam-se os resultados relativos à atuação das variáveis sexo, escolaridade e idade sobre a palatalização de /1/.

\subsection{VARIÁVEL DIAGENÉRICA}

Seguem os resultados referentes á atuação do sexo sobre a palatalização:

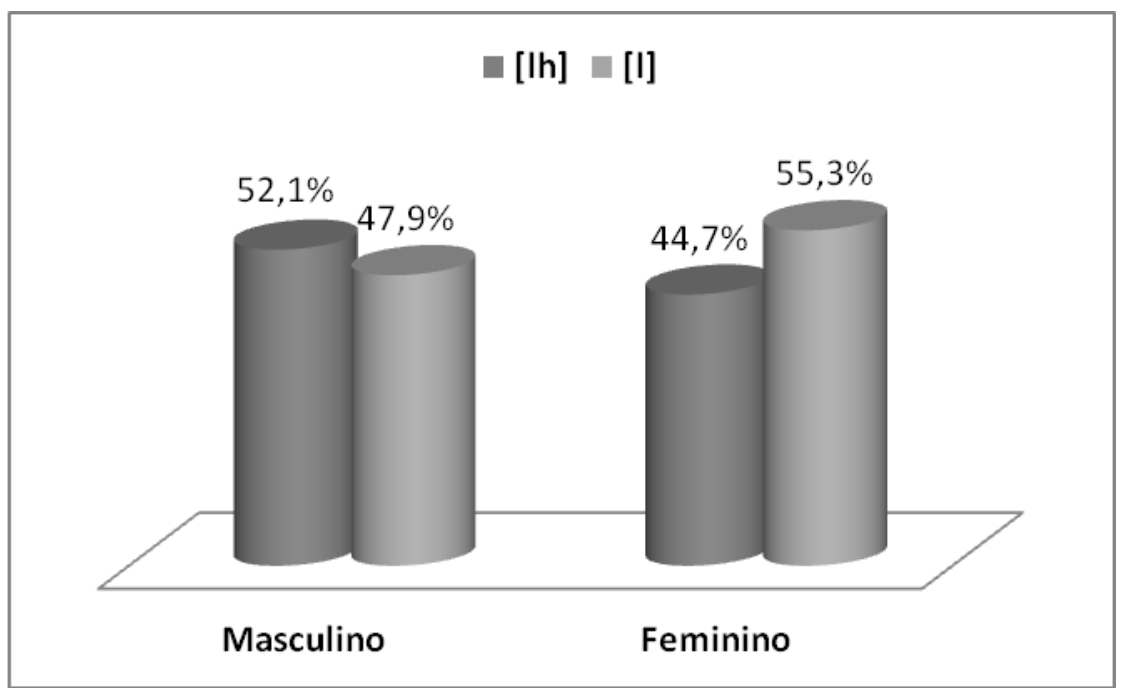

Gráfico 06: distribuição, por sexo, das variantes palatal e alveolar. 
Os resultados referentes à atuação do gênero revelam que os homens usam mais a variante palatal do que as mulheres. Elas apresentaram frequência de 44,7\% de variante palatal, enquanto eles, de $52,1 \%$.

\subsection{VARIÁ VEL DIAGERACIONAL}

Os resultados relativos à faixa etária dizem que os jovens usam mais a variante palatal do que os mais velhos, conforme se pode visualizar no gráfico 07 :

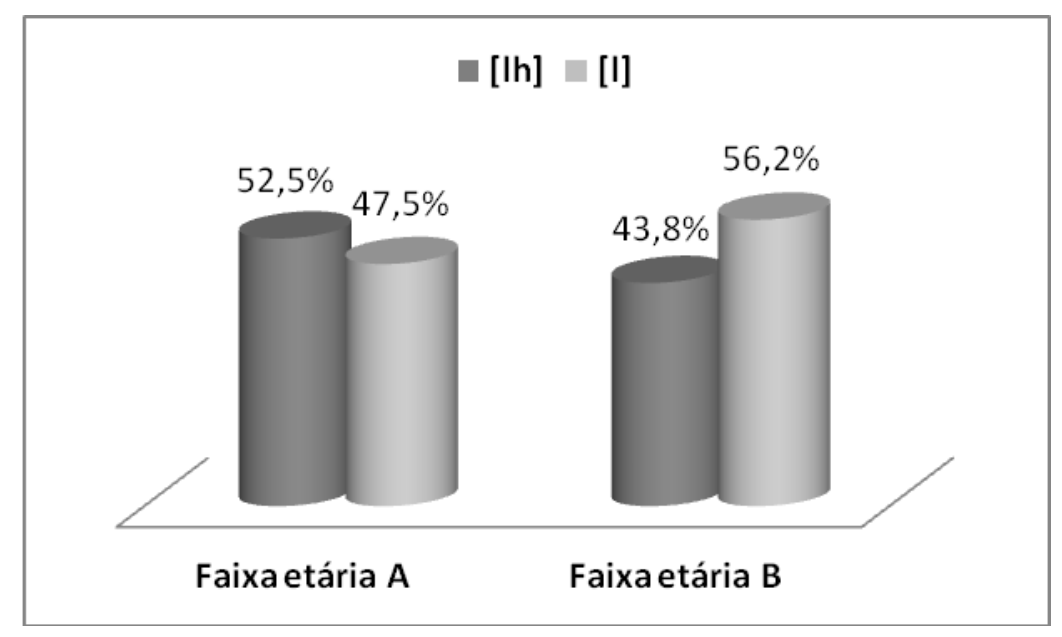

Gráfico 07: distribuição das variantes palatal e alveolar em função da idade.

A faixa etária A apresenta frequência igual a 52,5\%; a faixa etária B, igual a 43,8\%. Esse resultado sugere que a variante palatal pode se constituir uma tendência de mudança, pois já é mais usada pelos mais jovens.

\subsection{VARIÁVEL DIAFÁSICA}

Como as duas outras variáveis sociais apresentadas, a variável escolaridade também apresenta efeito diferente sobre a palatalização. Veja-se o gráfico que segue:

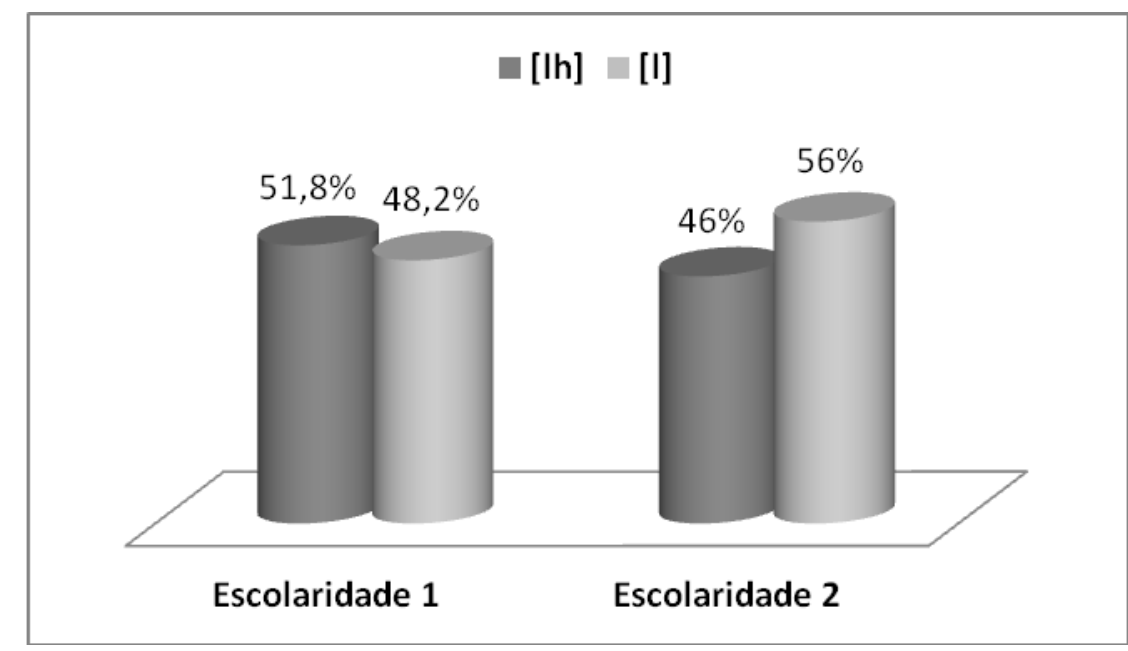

Gráfico 08: distribuição, por escolaridade, das variantes palatal e alveolar.

Os falantes de escolaridade 1 (os que têm o ensino fundamental) palatalizam mais que os falantes de escolaridade 2 (os que têm ensino universitário). 
Tem-se $51,8 \%$ de palatalização para os falantes de ensino fundamental e $46 \%$ para os de ensino superior. A diferença de uso nas duas escolaridades é mais acentuada entre os indivíduos mais escolarizados.

Dentre as três variáveis sociais controladas, a faixa etária foi a que se mostrou mais atuante (a diferença de palatalização entre a faixa etária A e B foi de 8,7\%). A variável sexo também se mostrou relevante (com diferença de $7,4 \%$ entre a fala dos homens e a das mulheres), já a variável escolaridade se mostrou pouco relevante (com diferença de 3,3\% de ocorrência de palatalização entre os falantes de escolaridade 1 e 2).

\section{CONCLUSÕES}

Como se pôde observar, a estrutura silábica exerce grande influência no processo de palatalização do /l/. Dos 367 dados que apresentaram a estrutura CVV, apenas 9 ocorreram como $[\lambda]$, o que demonstra um índice acima de $97 \%$ de palatalização. Devido a esse percentual altíssimo, ao fato de as palavras com estrutura CVV serem basicamente três (família, sandália, mobília) e ao fato de o objetivo principal deste trabalho ser o mapeamento diatópico da palatalização de /1/ no Brasil, esses dados foram retirados da análise, sendo considerada apenas a estrutura CV na análise final.

Dessa forma, portanto, os resultados apresentados demonstraram que a palatalização de /l/ já está bem arraigada no território brasileiro, prestando-se à caracterização diatópica do PB. De um lado, tem-se o Norte com uso expressivo de palatalização e, de outro, o Nordeste com resistência clara ao fenômeno. Sul, Sudeste e Centro-oeste apresentam uso intermediário da variante palatal. Quanto às variáveis sociais (idade, sexo e escolaridade), elas demonstraram que os indivíduos entre 18 e 30 anos, homens e de escolaridade 1 são os que mais palatalizam.

Entende-se ser importante que a palatalização de /1/ não seja vista dissociada dos demais fenômenos de palatalização do PB, haja vista que, como foi demonstrado, há forte tendência de condicionamento da palatalização quando algumas condições fonético-fonológicas se fazem presentes (p. ex., a presença de $[\mathrm{i} / \mathrm{j}]$ no contexto seguinte). $\mathrm{O}$ que acontece com o /1/, portanto, não é muito diferente do que acontece com o /t/ e /d/ antes de [i], fenômeno este já amplamente documentado.

Todavia, ressalta-se que, da mesma forma que os fatores estruturais permitem reunir fenômenos e fazer generalizações descritivas, os fatores extralinguísticos também permitem essas generalizações. Nesse sentido, é importante notar que a preponderância da variante palatal no Norte descreve um padrão ou uma tendência (ou preferência) de uso que é bem coerente com os demais fenômenos de palatalização na região, tais como [t]]ia, [dz]ia, co[f]ta, ve[3]go. O mesmo é válido para o Nordeste, com relação à preferência pela não palatalização.

\section{REFERÊNCIAS}

Camara Jr., J. M. 1977. Para o estudo da fonêmica portuguesa. $2^{\mathrm{a}}$ ed., Rio de Janeiro, Padrão. Cardoso, S. A. M. da S. C. et al. 2014. Atlas Linguístico do Brasil. v. I e II. Londrina, EDUEL. Oliveira, M. B. de. 2007. Palatalização da lateral alveolar /l/ em posição prevocálica em Itaituba$P A$, Tese de Doutorado, Universidade Federal de Alagoas. Maceió. Inédita

Teyssier, P. 2001. História da língua portuguesa. $2^{\text {a }}$ ed., São Paulo, Martins Fontes. 